Bangladesh Journal of Bioethics 2010;1(3) :35-42

\title{
ORGAN TRANSPLANTATION AND VULNERABLE DONORS: DONATION UNDER EMOTIONAL COMPULSION
}

\author{
Inayat Ullah Memon
}

Chief Pathologist, Peoples Medical College Hospital, Nawabshah, Sindh, Pakistan.

Email: memon.inayat@gmail.com

\begin{abstract}
During last few decades advancements in medical knowledge and technologies have increased the practice of organ donation. Organ transplantation, on one hand gifts renewed life to the donors, while on the other hand unwanted ethical practices in the field exploit vulnerable donors, such as trend of 'transplantation tourism' involving non-related live donors. Beyond this, some delicate and intriguing situations bring the physicians at cross-roads in cases of live related donors' transplantation. In this paper, I would like to discuss and analyze a case of live donor (un-married girl), where overtly consents to donate kidney to her brother who is breadearner of their joint family. By consenting to donate, the girl jeopardizes her matrimonial proposal as her fiancé is uncertain about her post-donation health status. The transplant clinician, aware of this fact faces ethical dilemma, whether to perform transplantation surgery so as save the life of ailing patient or to abandon it in order to save the future marriage of the girl from being broken. The case highlights multiple ethical issues in Asian socio-cultural context. I have attempted to disentangle the dilemma by applying Mc Donald and Rodney's framework of ethical decision making.
\end{abstract}

Introduction: Since the first kidney transplantation in early fifties of twentieth century, that was associated with some complications, the practice of kidney transplantation have progressively increased due to development of interventions that increased acceptability of foreign organ, introduction of leading-edge surgical procedures that are more comfortable as well as safer for both donor and recipient, with subsequent improvement in quality and increased volume of transplantation procedures in coming years. ${ }^{1,2}$ From ethical perspective, though cadaveric organ donation is less problematic than acquisition of organs from live donors, but this category of donation alone can't meet the growing demands for the end-stage renal failure patients. ${ }^{3}$ Much has been debated about ethics of non-related organ donation. In developing and poor countries, extreme poverty, non-existence or ineffective legislation governing this procedure and presence of influential organ-trade brokers in collaboration with some medical professionals have opened the avenues leading to 'transplantation tourism', which is coupled with overt and undesirable unethical practices. ${ }^{4,5}$ Alternatively, the ethically preferable and medically favorable mode of transplantation i.e. live-related donation is not absolutely free from ethical downsides. On one hand the related donors have technically more chances of compatibility than non-related donors, while on the other hand some subtle ethical intrigues are frequently encountered in this type of donation than more obvious moral problems associated with non-related type. Acquisition of genuine, valid, truly voluntary and coercion-free informed consent from donor is ethical pre-requisite. ${ }^{6}$ Role of compelling emotions by the donor towards related organ recipient is not only natural, provides psychological satisfaction to the donor as sharing the illness of the patient and is commendable act as well. Living organ donation has 
unique characteristic i.e. for the well being and life of the ailing person, a healthy donor is put at potential risks. ${ }^{1,2}$ Witnessing by the transplantation team the impulsive and hurried decision of relatives to donate organs generates concerns about the validity of consent. Some authors argue that participation in clinical trials have similarities with donating organs for nears and dears but there are unjustifiable differences while obtaining informed consent from these two groups of altruistic people. In organ donation the members of transplantation team have conflict of interest in the form of inherent sympathies for the organ recipient that makes the consent taking procedure questionable. ${ }^{1,6}$ The most worrisome factor in the process of donor's consent in transplantation procedure is whether it is free from impulsive and compelling emotional forces generated due to the close relationship with prospective recipients and sympathy toward them. Does the donor ignore associated risks because of these forces? Does the donor's decision-making ability is adversely affected because of financial dependence (as in the following case) on the recipient? Does the donor, being close relative of the recipient have no alternative but to submit herself to the wishes of the family (which is not uncommon phenomenon in Eastern context) so as 'save the face'? ${ }^{6,7}$ Moreover is the donor fully aware of all the possible outcomes of the proposed transplantation, including failure of the procedure or possible death of the recipient and potential risks and hazards resulting from his/her nephrectomy? ${ }^{1,2}$ Uncertainty in the medical fraternity about the risks associated with kidney donation, particularly the long-term long term such as hypertension, diabetes and chronic kidney disease, with ethnic variations, further compounds the issue. ${ }^{2,8,9}$ To address these questions, an environment is required to exclude the potential weaknesses associated with procedure of obtaining informed consent by the transplantation team and offered by the donor in these special circumstances. In Eastern socio-cultural context, where transplantation team is more trusted by the donors as well as recipients who customarily exercise lesser autonomy in contrast to rights-based Western society, the responsibilities of the transplantation clinician are enhanced in order to resolve ethical issues and help both partners of the transplantation procedure and their families to arrive at morally acceptable outcomes. Following case explains a situation, similar to which are not infrequently encountered in developing countries where the transplantation teams face a dilemma. Cases like these need to be assessed by some recognized frameworks of ethical decision-making. I have made an attempt to disentangle the issue by using Mc Donald and Rodney's framework. $^{10}$

Case study: Mr. "P" (patient) suffering from renal failure is admitted to specialized Transplantation Hospital, KTC (Karachi Transplantation Centre, not the real name) in Karachi, Pakistan, where he is undergoing hemodialysis. He is 42 years aged man, belongs to poor socio-economic group. His father Mr. "F" (father) is 65 years old and alive, while had mother has passed way a few years ago. Mr. "P" is married, his wife Mrs. "W" (wife) is happy and healthy, has two children, one boy and one girl. Mr. "P" has one sister Miss " $\mathrm{S}$ " (sister), who is unmarried (her marriage is planned after about six months), aged 25 years and has one brother " $\mathrm{B}$ " (brother) 35 years old. Miss " $\mathrm{S}$ " is illiterate house woman, not engaged in any job. Being a joint family, all live together and are financially dependent on "P" who has/had been the bread-winner. Doctors have advised "P" for renal transplantation. As an initial step "S", "B" and "W" were investigated for compatibility to donate kidney to "P". The workup reveals that only his sister " $\mathrm{S}$ " is compatible, the results were communicated to the family. After a few days, 
the Dr. "U" (urologist, member of transplantation team) called a meeting with all concerned people in this case i.e. Miss "S", Mr. "F" and Mrs. "W" and Mr. "B". "S" was informed that she has been found the appropriate person amongst the three to donate kidney to her brother. She does not show any sign of apparent displeasure or disagreement for the procedure, her father " $F$ " also agrees for her kidney donation. After three days, a person Mr. "FI" (fiancé) came in the office of Dr "U", introduced himself as fiancé of Miss "S", informed Dr "U" about his concerns regarding kidney donation of "S" for "P". He raised objection on the willingness of the family of "P" for the transplantation. He politely informed Dr. "U" that if her kidney is removed for donation, he will not marry with " $S$ " because her health would deteriorate. Doctor listened to him carefully and told that his views will be given due consideration, doctor "U" also discussed with him about his ("FI") fears of health deterioration after kidney donation and explained that so far no major adverse health consequences have been reported by kidney donation, if the donor is carefully looked after. Mr "FI" did not make any comment after Dr "U" "s explanation, but Dr "U" guessed from his nonverbal behavior that "FI" has not changed his views even after the explanation.

Dr. "U" faces ethical dilemma in this case. He wonders what he should do. Should he accept the kidney of "S" for "P" (to save the life of patient) despite objection of her fiancé? Or advise the relatives of "P" to seek and arrange some other compatible donor. The family is not financially sound to compensate un-related donor for kidney donation. The family is unable to bear the expenses of long-term haemodialysis. Neither, "P" is insured for his health, nor there is state social welfare system to bear the financial cost of dialysis. At the same time, he is aware of the fact that if kidney of " $\mathrm{S}$ " is removed "FI" would not marry with her. Moreover he is familiar with local customs and traditions that once her engagement is broken with bearing this stigma the chances for her matrimony are very bleak and he is aware of the fact the prospective donor ("S") is financially dependent on recipient ("P") that further deepens ethical issue. Dr " $U$ " is under pressure from the family of "P" to perform transplantation surgery early so as "P" returns to routine life and provide earnings for the family.

To resolve this issue and in the best interest of "P" and prospective donor "S", Dr " $U$ " thought it better to arrange a meeting with " $S$ " and her father " $F$ " so as to disclose and discuss with them views expressed by "FI". Meeting was held and Dr "U" came to know that " $F$ " and "S" were already aware of "FI"'s disagreement and both were overtly happy if "S" s kidney is transplanted to "P". Dr " $U$ " attempted to have meeting with Miss "S" in privacy, so as to assess her free will of donating kidney and exclude the factor of coercion by her relatives, if any, but he couldn't succeed because of cultural inhibitions.

\section{Ethical analysis of the case:}

First, I would like to identify the ethical issues in the case followed by their analysis using the framework of McDonald and Rodney, which includes within its larger framework the 'four boxes' clinical ethical analysis of Jensen et al. This framework has four components i.e.

A. Collection of information and identification of the problem. This includes four factors of Jonsen, Siegler and Winsdale ${ }^{11}$ (Medical indications, Patient's preferences, quality of life and contextual factors)

B. Specification of feasible alternatives

C. Use of ethical resources to identify morally significant factors in each alternative 


\section{Making the choice}

Ethical issues: 1. Is the donor (being a lady/a vulnerable member of the community and financially dependent on prospective recipient) truly autonomous, genuinely free and emotionally neutral to give voluntary informed consent? 2. Is she able to make her own decisions in the background of the fact that her father and brother would be unhappy, if she declines to donate kidney? 3. If she donates the kidney, what would be the fate of her prospective marriage? 4. Is she well informed about the possible adverse consequences of the kidney donation?

Let us discuss each issue separately:

1: Given the fact that " $\mathrm{S}$ " is financially dependent on his brother " $\mathrm{P}$ " and is part of an intricately woven joint family, it appears very impracticable for her to decline to donate kidney (to genuinely exercise her autonomy), even if she decides to do so. Now let us further explore this issue in context of developing countries. Presuming that donor is male, bread-winner of the family and financially supporting joint family, then what would hypothetically be the voluntary decision of a brother for his sister who needs kidney for transplantation. In general no brother or sister having equal social or financial standing will disagree for organ donation for his/her brother/sister, if this process has no bad health consequences for donor. That is demand of the doctrine of "Ethics of Care"2. It is the brother-sister relationship (like any other close bondage) which attracts more care for each other out of love. These situations do not involve any apparent influencing / coercing factors on close relatives to donate the organs. But when viewed in context of poor developing countries, the read-winning brother would hardly sacrifice his precious organ to save the life of his sister having low financial value.

2: Is she emotionally neutral to make decision about kidney donation (neuroethics). This aspect of the case needs further exploration. It can be appreciated that one's emotional situation, previous experiences and context do affect the decision-making ability. As described by Moll and Crafman" in their "Event-Feature-Emotion" complex, interplay of different parts of brain (i.e. pre-frontal lobe, temporal lobe and limbic system) results in ethical decisions making. Limbic system being concerned with emotions does affect the ultimate decision. Moreover, they assert that person's background (exemplified by orphan child) will affect the decision as well. Likewise in this case, she can't be considered emotionally neutral. Prospective kidney recipient is the bread-earner of the family and his sister is the only compatible match amongst three available donors. Will not this situation compel her to donate? Moreover process of decision making varies with social and cultural context. ${ }^{13}$ I mean to say that Western individual-based autonomy can neither be expected from Eastern society nor it is practiced to that extent as in the West. In Eastern culture a man is considered superior while women is given secondary status, this fact becomes even harder where the literacy rate and socio-economic condition go down. In this background and the fact that she is not earning member of the family, if she declines to donate kidney, there are strong fears that her father and brother would not only be unhappy but angry. She being a part of this culture would be aware of this fact. Will this affect her ability of decision making? 
3: Another factor is fate of her matrimony. If she donates kidney there are strong chances that her fiancé would refuse to marry with her as her fiancé has already expressed his views about the proposed transplantation. This is generating producing conflict in her mind (a conflict of interest), either to save the life of her ailing brother and 'save her face' in family and society or for the sake of her matrimony refuse to donate.

4: The root problem that created the dilemma is the issue of adverse consequences on donor's health after nephrectomy, because this is the issue that prompted "FI" to contact Dr "U". According to Canadian scientist, issue of knowledge and assessment of medical consequences of organ donation is important one, as he said: "A more precise understanding of the long-term medical outcomes is critical for improving donor selection, informed consent and follow-up" "14. Though there are few post-donation risks of lesser gravity, but still there is no complete and high-volume studies available on record for the ethnic minorities in USA and for the people of developing countries; that hinders the ethically compete disclosure of information to the donors so as to allay their fears if any.

While analyzing the issue of girl's consent for donation, it is important to assess the validity of her informed consent, to inform her about health related consequences of kidney donation, available alternatives and possible chances success/failure of transplantation surgery. I am afraid this issue is not faithfully dealt with at least in developing countries. The legal formalities are fulfilled, donors' willingness is taken just in the form of signature (or thumb impression) but requirements of understood and informed consent are not met. I would like to refer here two episodes of program televised about kidney selling/donation, shown on local TV network in Pakistan on $14^{\text {th }}$ and $21^{\text {st }}$ April 2007 (08-05 PM), wherein surgeon said that he used to tell to the donors all the things about removing kidney and further explained that he had documentary proof of that. He stressed on documents but gave very little importance to the ongoing process of informed consent. ${ }^{15}$

\section{Analysis in Mc Donald and Rodney's Framework:}

A. Collection of information and identification of the problem: It will be appropriate to apply the 'four boxes' of Jensen et al on both the patient (organ recipient) and donor. Regarding medical indications, from the patient's perspective, the process of kidney transplantation fulfils the goals of medical treatment i.e. there are bright chances of recovery of the patient from renal failure while from the donor's perspective in general there are only few (if any) chances of damage to her health and these are same to as to any other donor in case of kidney transplantation. But lack of data and absence of studies regarding long-term post-nephrectomy consequences for donors of developing countries makes the issue more problematic. As far patient's preferences are concerned, the he wishes with his full senses, to have the kidney transplanted to him and it is informed, understood and voluntary. While it is uncertain if the donor's consent is genuine and informed or given under emotional coercion, duress or family compulsion. Regarding patient's quality of life, it would improve both in the view of patient and the caregiver (transplantation clinician), moreover it is worthwhile to perform this process as it is internationally recognized mode of treatment for the end-stage renal failure. But from the donor's perspective it is doubtful, being a 
woman she has slightly more chances of developing hypertension related disorders of pregnancy moreover belonging to poor socio-economic group makes it uncertain that she would be properly looked after in case her health deteriorates. ${ }^{2}$ Regarding contextual features, transplantation will improve the economic condition of the recipient's family, as he is the bread earning member. But it is doubtful if the family would be able to bear the expenses of ongoing treatment of the recipient after transplantation. From the donor's perspective, she will be in a fragile situation, as recipient being the bread-winner will be preferentially looked after than the donor in case of illness.

B. Specification of feasible alternatives: For the patient the possible alternatives are either to have transplantation performed or to continue the haemodialysis. But the second option because of economic constraints is not feasible for the family. This factor also applies to the physician, if he performs the transplantation surgery he will knowingly jeopardize the matrimonial proposal of the donor but on the other hand if he doesn't, then he will increase the miseries of the renal failure patient. This situation brings the physician at cross-roads.

C. Use of ethical resources to identify morally significant factors in each alternative: When physician applies four founding bioethical principles of Beauchamp and Childress, he faces a dilemma. Veracity of informed consent of the donor is tinted due to many reasons, including disclosure of insufficient and uncertain information about post-donation risks for donor, ${ }^{2,8,9,16-18}$ She, because of her peculiar position in the society and in the family is unable to exercise her innate autonomy. As the donor will benefit from the process of transplantation, thereby physician fulfils requirement of beneficence, but lesser attention is paid to the women folk in our society will make the donor medically more vulnerable which will negate non-meleficence, another principle of bioethics. Regarding justice, what the society and the medical profession will do in case the donor is brother and the recipient is sister who is not in a position to bring monetary benefit to the family. Will the members of the society permit this transplantation if some important event of life (such as marriage) of the male donor is at risk due to this process?

D. Making the choice: In this case the transplantation clinician has two choices, either to perform the surgery for the health of the patient or to refuse the procedure due to ethically questionable consent of the donor. To pave the way for decision the surgeon utilized his efforts to persuade the fiancé of donor not to object and by explaining that there are minimal chances of adverse effects to the donor's health of donor. This framework, fortunately allows the decision maker (transplantation surgeon) to select a better choice amongst the available ones, the chosen one may not necessarily be the best, but transplant clinician still has to decide which is better choice in Eastern perspective. Dilemma has still remains un-resolved!

Though Mc Donald and Rodney's framework has obvious and convincing strengths in the process of ethical decision-making but it is not free from weaknesses. Application of the framework in this particular case, though involves all the stakeholders in decision making which is ethically required ${ }^{19}$ but the particular situation where parents of donor and recipient are not only willing but eager for early procedure with questionable consent of the vulnerable donor brings the onus of ultimate decision on the shoulders of transplantation surgeon. This framework does allow the clinician to 
make choices between available options, as well as taking the responsibility of decision. Therefore by using this framework, one can reach at some conclusion. In cases of live related donor transplantation, the four boxes of Jonsen et al ought to be applied in both involved persons i.e. patient and donor. The results of application of two boxes amongst the four i.e. preferences and quality of life, four boxes, on two persons (donor and patient) are inherently opposing and conflicting (when donor's interests are protected the recipient's interests are jeopardized) as it involves a process of organ transfer from one member of the pair to another, that makes the decision difficult. This requires more suitable frameworks that can meet the needs of dilemmas like one presented in this paper.

\section{Conclusion:}

This case presents one of the many unique issues characteristic of developing, particularly poor countries, where specific cultural traditions, tribal customs, societal factors, poverty and legislative weaknesses facilitate undesirable and unethical practices to flourish. The vulnerable groups of the population are easy prey to undesirable organ transplantation practices, a ethical problem shared by clinical research mal-practices. More obvious, overt and loudly heard issues like 'transplantation tourism' have attracted the attention of clinicians and bioethicists since many years but subtle ethical issues attached to live-related organ donations by weak and silent family members or relatives such as mentally retarded or unknowledgeable females deserve attention of society leaders, clinicians and other stakeholders. Mere obtaining of documentary informed consent is neither sufficient nor the required condition. We need to as sincerely and honestly safeguard the donors' interests as we ethically protect the wellbeing of our organ-recipient patients.

\section{References:}

1. Perrir A, 'Ethic committee validation of live donor consent: is it any use?'Bioethica Forum, 2009, vol. 2, No. 2, pp. 92-97

2. Reese PP, Friedewald JJ, 'Profiling live kidney donors in America: Cause of optimism and concern', Clin J Am Soc Nephrol, 2010, vol. 5, pp. 1732 - 1733.

3. Truog RD, 'The effects of organ donation by living donors', $N$ Eng $J$ Med, August 2005, vol. 353, no. 5, pp. 444-446

4. World Health Organization (WHO) Bulletin, 'Dilemma over live-donor transplantation' http://www.who.int/bulletin/volumes/85/1/07-020107/en/\#

5. Denneman L, Mol M, Is legalizing commercial kidney donation medically-ethically justifiable?, Organ trade: a win-win situation or exploitation in disguise? 'Global Medicine', http://globalmedicine.nl/index.php/currentedition11/206-organ-trade-a-winwin-situation-or-exploitation-in-disguise

6. Truog RD, 'Consent for organ donation: Balancing conflicting ethical obligations', N Eng J Med, March 2008, vol. 358, no. 12, pp. 1209-1211 
7. Abecassis M, Adams M, Adams P, Robert M, Arnold, Carolyn R, et al, 'Consensus statement on the live organ donor, JAMA, 2000, vol. 284, No. 22, pp. 2919 - 1926

8. Drukker A, 'Unilateral nephrectomy: The adverse effects of live kidney donation', ASSIA, Jewish Medical Ethics, Feb 2001, vol. IV, no. 1, pp. 7-8.

9. Lentine KL, Schnitzler MA, Xiao H, Saab G, Salvalaggio PR, Axelord D et al, 'Racial variation in medical outcomes among living kidney donors', $N$ Eng $\mathrm{J} \mathrm{Med}$, August 2010, vol. 363, no. 8

10. McDonald M, 'A Framework of ethical decision-making: Version 6.0 Ethics Shareware. Jan 200.

$<$ www.ethics.ubc.ca/.../A\%20Framework\%20for\%20Ethical\%20Decision-Making.pdf - $\underline{\text { Similar }>}$

11. Jonsen AR, Siegler M, Winslade WJ. "Clinical ethics: A practical approach to ethical decisions in clinical medicine'. 2006, 6th ed. New York: McGraw-Hill.

12. Moll J, 2005 'Ethical decision-making', A new Review, Brain Ethics, $<$ http://brainethics.wordpress.com/2005/11/>

13. Jennifer Mencl, 2007, 'Moral emotions and ethical decision making', Presentation at: Business Ethical in a Global World: China, India and beyond. Markkula centre for Applied Ethics, Santa Clara University, March 10, 2007.

http://www.scu.edu/ethics/practicing/focusareas/business/conference/2007/presentation s/

14. Lawson in the News, "Study to look at long-term implications of becoming a kidney donor", May 12, 2005.

http://www.lhrionhealth.ca/LHRI/news/News Articles 2005/news 0512 05.htm

15. TV Talk on 'GEO' Television network, with Transplant surgeons on $14^{\text {th }}$ and $21^{\text {st }}$ April, 8-00 PM, 2007.

16. Petrinin C, 'Ethical issues in informed consent from potential living kidney donors', May 2010, Transplantation Pro, May 2010, vol. 42, no. 4, pp. 1040-1042.

17. National Health and Medical Research Council (NHMRC), Australia, 'Some important ethical issues to be considered', Ethical issues in organ donation, Discussion paper No. 2.

18. Fazel I: 'Renal transplantation from living related and unrelated Donors, Transplant Proc, 1995, vol. 27, pp. 2586-2587.

19. American Medical Association (AMA), Professional Resources, Medical Ethics, Clinical Case 3, 'Finding the balance in shared decision making',

$<$ http://www.ama-assn.org/ama/pub/category/11848.html $>$ 